\title{
Preventing and Managing Burnout: What have we learned?
}

\author{
Shailesh Kumar* \\ Consultant Psychiatrist, University of Auckland, New Zealand
}

Received: January 16, 2018; Published: January 30, 2018

*Corresponding author: Shailesh Kumar, Consultant Psychiatrist, Waikato District Health Board, Honorary Clinical Associate Professor, Waikato Clinical Campus, University of Auckland, Hamilton, New Zealand, Tel: 6478398899; Email: Shailesh.kumar@waikatodhb.health.nz

\begin{abstract}
Burnout is a psychological response to exposure to chronic stressors at work and is characterised by high levels of emotional exhaustion, depersonalisation and reduced personal accomplishment. Expression of burnout is said to be mediated by internal and external factors that act in predisposing, precipitating, perpetuating and protective roles. Active screening for burnout in employees using affective, cognitive, behavioural and motivational signals helps raise awareness and ensure prompt intervention is offered. Systematic reviews have identified the significance of combining individual and organisational intervention strategies which appear to work best if intensive and booster sessions are offered in conjunction.
\end{abstract}

Keywords: Burnout; Organisational stress; Workplace stress; Screening

\section{Introduction}

Burnout is a psychological response that often develops when a person, often working in the human services profession and having to deal with people, is exposed to chronic emotional and interpersonal stressors at work. The most widely accepted definition of burnout conceptualises it as a construct of three dimensions: emotional exhaustion, depersonalisation and decreased personal accomplishment [1]. There is some evidence to suggest that the prevalence of burnout in many professions may be on the rise [2] and indeed may have reached "epidemic proportions" [3]. Certain recent societal changes may have contributed to the rise in burnout in health professions include patients have evolved to being fully dependant to equal partners in medical decision making, decreased job security due to changes in health care organisations [4].

\section{Why Does Burnout Develop}

The impact of exposure to chronic stressors at work in the healthcare environment has been a topic of much interest and speculation. According to [5] the final outcome of exposure to stress is mediated by internal and external (e.g. support systems) factors. Five internal factors [1] have been identified as contributing to burnout: hardiness, locus of control, coping styles, personality type and attitude. Low levels of hardiness or a lesser sense of control over events and unwillingness to accept change and greater degree of external locus of control may be more susceptible to burnout. Active and effective coping, on the other hand, is associated with less burnout. Some other internal risk factors have also been identified and include personality characteristics [6], an attitude of high expectations, propensity to work too hard-both leading to exhaustion and cynicism; perfectionism [7], a pessimistic view of the world and oneself, the need to be in control and reluctance or refusal to delegate [8], a need to please others, work as a substitute for social life [9], over-involvement with clients [7].

While such varied internal factors have been identified they are often difficult to measure. Demographic variables such as age gender ethnicity on the other hand are easier to measure but yield inconsistent findings in studies examining their relationship with burnout [10]; as can be seen from this review much research effort has gone in elucidating individual risk factors that increase the risk of burnout. While such studies have been helpful in developing our understanding of the pathogenesis of burnout three points of caution need to be exercised: firstly focussing on internal or individual risk factors runs the risk of portraying burnout as a sign of individual weakness or fallacy; secondly, they may also divert attention from studying the environmental factors that may have contributed to the onset of burnout in the first place and thirdly these studies report association and not causation between the risk factor and burnout.

It is, therefore, refreshing to see research has found environmental factors to be associated with risk of burnout. Having 
to frequently deal with the trauma and tragedies of clients and the chronicity and complexity of client problems [9] working with difficult or unpleasant patients [10] and working with vulnerable populations are work environment risk factors that specifically related to client groups health professionals work with that are attributed to burnout [11]. The absence of job autonomy / control (i.e., overall decision freedom in a job) also leads to more burnout [8] found. "When people do not have control over important dimension of their job, it prevents them from addressing problems that they identify...Without control, they cannot balance their interest with those of the organization." Similarly, [12] found lack of feedback on the work performance; meaningful rewards and a lack of job security were work conditions with "burnout potential". Sagely, Maslach et al. suggested whole organizational context should be considered when examining burnout favouring conditions.

\section{Understanding the Evolution of Burnout}

Differences in personalities, training and types of stressors experienced or job satisfaction may need to be considered in drawing conclusions from diverse range of populations such as lawyers, rehabilitation workers and public service employees and psychiatrists [13]. Certain professional groups such as psychiatrists may tend to score high in job satisfaction surveys despite experiencing depression and burnout [14-17]. In an attempt to bring together individual and organisational risk factors for burnout an aetiological model of burnout proposed certain factors may predispose, precipitate, perpetuate or protect against burnout. Predisposing factors include: personality characteristics, the mismatch between training and working environments, and an ever-increasing workload. Precipitating factors include violence perpetrated by patients, suicide committed by their patients, oncall duties and dealing with difficult and hostile relatives. a lack of resources may as well lead to burnout. Especially, not having enough support from supervisors and co-workers increases the possibility of having burnout.

Perpetuating factors include a subjective feeling of being overworked, feeling poorly managed and resourced, dealing with patients suffering, gender (the way men versus women respond to stressful situations) personality attributes, changes in health service delivery model, clinician management conflicts, time management and resource issues. Protective factors include paying attention to one's non-professional life and academic work. Similarly, Holloway et al. examined the relationship between external stressors, mitigating or protective factors and outcomes such as burnout and reported that the final outcome of exposure to stressors varies depending on the interaction between these factors. Both these models were theoretical and it remains to be seen whether exposure to such stresses does actually lead to adverse health outcomes.

\section{Screening and Preventing Burnout: An Organisational Responsibility}

Burnout develops in work setting. Raising awareness about it can go a long way in preventing and managing it. Regular screening for burnout can be a crucial step in raising awareness as well as offering help for the affected staff in a timely fashion. [1] highlighted the significance of looking out for signals of mental or emotional exhaustion, mental and behavioural signals (rather than physical) and decreased self-efficiency. It is also worth keeping in mind that burnout invariably presents itself in populations who are otherwise hard working and generally psychologically well-adjusted [1]. Such population groups may not be forthcoming with reports of changes in subjective wellbeing. External or organizational monitoring becomes a necessity for these reasons when it comes to monitoring burnout [18]. Enlisted signals at interpersonal level that may be helpful in organizational efforts to screen burnout. They categorize such signals into affective, cognitive, behavioural and motivational domains. Since physical signals can be observed only on individual level, they are excluded.

\section{Screening for Affective Cognitive Behavioural and Motivational Signals of Burnout}

\section{Affective Signals:}

a) Irritability

b) Being oversensitive

c) Lessened emotional empathy with clients

d) Increased anger

Cognitive Signals:

a) Cynical and dehumanizing perceptions of clients

b) Negativism / pessimism with respect to clients

c) Labelling clients in derogatory ways

\section{Behavioural Signals}

a) Violent outbursts

b) Irritability toward clients

c) Interpersonal, marital and family conflicts

d) Social isolation and withdrawal

e) Responding to clients in a mechanical manner

\section{Motivational Signals:}

a) Loss of interest

b) Indifference with respect to clients

Screening efforts alone may not be adequate for identifying those affected by burnout. Two reliable and validated tools are widely used for measuring or quantifying burnout once it sets in: Maslach Burnout Inventory- MBI [9] and Copenhagen Burnout Inventory-CBI [19]. These tools have been used in research as well as clinical settings. Improved ability to detect the condition through standardisation of definition, societal acceptance of the construct, good screening efforts and reliable rating may have contributed to the acceptance of burnout in mainstream medicine. Some European countries including the Netherlands and Sweden have accepted 
burnout as a medical entity and have specialist services for treating the condition [2]

\section{Managing Burnout}

In keeping with the acceptance of burnout as a clinical entity several studies have evaluated the effectiveness of treatment programmes for burnout. Two excellent systematic reviews have examined the effectiveness of various intervention strategies against burnout [20,21]. Interestingly enough, although stress management programmes are often suggested for managing staff burnout the systematic review by [20] found no evidence of effectiveness of brief stress management training interventions in reducing job stress for health workers. However, the authors did find low quality evidence to support the effectiveness of stress management training of moderate intensity (defined as more than six hours contact over one month) in short term reduction of job stress levels but the beneficial effects diminished without booster sessions. The review found strong levels of evidence to support the effectiveness of intensive, long term stress management training programmes in reducing the job stress and risk of burnout among a wide range of health workers working in a variety of settings.

Future studies of intervention studies in burnout may wish to compare the efficacy of long and short term programmes of varying intensities. The systematic review by [21] grouped intervention strategies against burnout into Person-directed (cognitive behavioural therapy, relaxation, music making, massage and multicomponent programmes) and Work-directed (attitude change and communication, support from colleagues, participatory problem solving and decision making, and changes in work organisation). The authors found there was only limited evidence to support the efficacy of either Person- or Work-directed intervention strategies in reducing burnout in healthcare workers but concluded that the benefits of such interventions may be evident for as long as two years. This review highlighted the need for good quality intervention studies for burnout.

Combining the two systematic reviews, one could speculate that an intense stress management programme with booster sessions delivered over a longer period may yield longer lasting results. There is evidence to suggest literature both individualfocused and structural or organisational interventions can result in clinically meaningful reductions in all dimensions of burnout. A recent systematic review by [3] of 2617 articles, of which 15 randomised trials found overall burnout decreased from $54 \%$ to $44 \%$ (difference $10 \%$ (95\% CI 5-14); $\mathrm{p}<0.0001$; I2=15\%; 14 studies), emotional exhaustion score decreased from 23.82 points to 21.17 points (2.65 points (1.67-3.64); $\mathrm{p}<0.0001$; I2=82\%; 40 studies), and depersonalisation score decreased from 9.05 to 8.41 (0.64 points $(0.15-1.14) ; \mathrm{p}=0.01 ; \mathrm{I} 2=58 \% ; 36$ studies). What was especially striking is high emotional exhaustion decreased from $38 \%$ to $24 \%$ (14\% (11-18); $\mathrm{p}<0.0001 ; \mathrm{I} 2=0 \% ; 21$ studies) and high depersonalisation decreased from $38 \%$ to $34 \%(4 \%(0-8)$; $\mathrm{p}=0.04 ; \mathrm{I} 2=0 \% ; 16$ studies) offering hope for those people who are experiencing particularly high levels of burnout. Literature does therefore offer optimism for those experiencing mild as well as severe levels of burnout.

\section{Conclusion}

Burnout among healthcare professionals is a serious and increasing problem. It affects staff, their families and the patients they care for. Screening for the conditions improves organisational awareness and may assist in early interventions. There are good tools for measuring burnout once it sets in. Treatment strategies that combine intense stress management programme with booster sessions delivered over a longer period may yield longer lasting results. Both individual-focused and structural or organisational interventions are needed for significant improvement in burnout levels once it develops or has been detected.

\section{References}

1. Maslach C, Schaufeli WB, Leiter MP (2001) Job burnout. In: Fiske ST, Schachter DL, Zahn-Waxer C (Eds.). Annual Review of Psychology 53: 397-422.

2. Schaufeli WB, Leiter MP, Maslach C (2009) Burnout: 35 years of research and practice. Career Development International 14: 204-220.

3. West CP, Dyrbye LN, Erwin PJ, Shanafelt TD (2016) Interventions to prevent and reduce physician burnout: a systematic review and metaanalysis. Lancet 388: 2272-2281.

4. Mechteld RM, Visser EMA, Smets FJ, Oort CJM (2003) Stress, satisfaction and burnout among Dutch medical specialists. Canadian Medical Association Journal 168: 271- 275.

5. Holloway F, Szmukler G, Carson J (2000) Support systems, Advances in Psychiatric Treatment 6: 226-237.

6. Chen H, Wu P, Wei W (2012) New perspective on job burnout: Exploring the root cause beyond general antecedents analysis. Psychological Reports 110: 801-819.

7. Sherman DW (2004) Nurses stress and burnout: How to care for yourself when caring for patients and their families experiencing life-threatening illness. American Journal of Nursing 104(5): 48-56.

8. Maslach C, Leiter MP (1997) the truth about burnout. Open journal of depression San Francisco: Jossey Bass.

9. Blom V (2012) Contingent self-esteem, stressors and burnout in working women and men. Work. 43: 123-131.

10. Beheshtifar M, Omidvar AR (2013) Causes to create job burnout in organizations. International Journal of Academic Research in Business and Social Sciences 3(6): 107-113.

11. Maslach C, Jackson SE (1981) The measurement of experienced burnout. Journal of Occupational Behavior 2: 99-113.

12. Schaufeli WB, Maslach C, Marek T (1993) Professional burnout: Recent developments in theory and research, Taylor \& Francis, Washington, USA.

13. Dombo EA, Gray C (2013) Engaging spirituality addressing vicarious trauma in clinical social workers: A self-care model. Social Work \& Christianity 40(1): 89-104.

14. Demerouti E, Bakke AB, Nachreiner F, Schaufeli WB (2007) the job demands resources model of burnout. Journal of Applied Psychology 86: 499-512.

15. Kumar S, Hatcher S, Dutu G, Fischer J, Ma'u E (2011) Stresses Experienced By Psychiatrists and Their Role in Burnout: a National Follow-Up Study. International Journal of Social Psychiatry 57: 166- 179. 
16. Snibbe JR, Radcliffe T, Weisberger C, Richards M, Kelly J (1989) Burnout among primary care physicians and mental health professionals in a managed health care setting. Psychol Rep 65: 775-80.

17. Prosser D, Johnson S, Kuipers E, Szmukler G, Bebbington P, et al. (1996) Mental health, burnout and job satisfaction among hospital and community-based mental health staff. Br J Psychiatry 169(3): 334-337.

18. Rey JM, Walter G, Giuffrida M (2004) Australian psychiatrists today: proud of their profession but stressed and apprehensive about the future. Aust N Zeal J Psychiatry 38(3): 105-110.

19. Vaccaro JV, Clark GH (1987) A profile of community mental health centre psychiatrists: results of a national survey. Commun Ment Health J 23(4): 282-289.

20. Schaufeli WB, Enzman D (1998) the burnout companion to study \& practice. Open journal of social sciences Taylor\& Francis, London, UK.

21. Kristensen TS, Borritz M, Villadsen E, Christensen KB (2005) The Copenhagen Burnout Inventory: A new tool for the assessment of burnout. Work \& Stress p. 19.
22.Van Wyk B, Pillay Van Wyk V (2010) Preventive staff-support interventions for health workers. Cochrane Database of Systematic Reviews.

23. Marine A, Ruotsalainen J, Serra C, Verbeek J (2006) Preventing occupational stress in health care workers. Cochrane Database of Syst Rev 18(4): CD002892.

24. Kumar S, Hatcher S, Huggard P (2005) Burnout in Psychiatrists: Etiological Model. International Journal of Psychiatry in Medicine 35: 405-416.

25. Lloyd C, King R, Chenoweth L (2002) Social work, stress and burnout: A review. Journal of Mental Health 11(3): 255-265.

26. Maslach C, Leiter MP (2005) Stress and burnout: The critical research. In: Cooper CL (Edn.). Handbook of stress medicine and health ( $2^{\text {nd }}$ Edn). CRC Press, London, UK, pp. 153-170.

27. Zedeck S, Maslach C, Mosier K, Skitka Linda (1988) Affective response to work and quality of family life: employee and spouse perspectives. J Soc Behav Personal 3(4): 135-157.
(C) (i) This work is licensed under Creative

Submission Link: http://biomedres.us/submit-manuscript.php

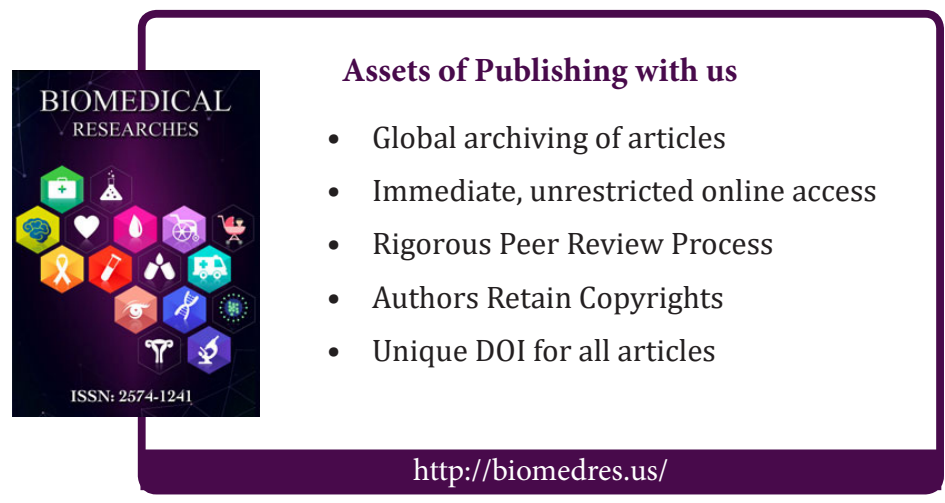

